\title{
Information Acquisition and Learning from Prices Over the Business Cycle*
}

\author{
Taneli Mäkinen ${ }^{\dagger}$ \\ Stockholm School of Economics
}

\author{
Björn Ohl ${ }^{\ddagger}$
}

Stockholm School of Economics

March 19, 2013

\begin{abstract}
We study firms' incentives to acquire costly information in booms and recessions to understand the role of endogenous information in explaining business cycles. We find that when the economy has been in a boom in the previous period, and firms enter the current period with an optimistic belief, the incentive to acquire information is weaker than when the economy has been in a recession and firms share a pessimistic belief. However, the price system, by transmitting information from informed to uninformed firms, dampens information demand and moderates the cyclicality of the aggregate learning outcome. Even though learning from equilibrium prices acts to stabilize fluctuations by discouraging information acquisition, it can be welfare-enhancing to make information prohibitively costly to obtain.
\end{abstract}

JEL codes: D51, D83, E32.

Keywords: information acquisition, rational expectations equilibrium, asymmetric information, strategic substitutability.

*We are grateful to Lars Ljungqvist, Christophe Chamley, Tore Ellingsen, Jungsuk Han, Ulf von Lilienfeld-Toal, Péter Kondor, Joël Peress, Morten O. Ravn, Pontus Rendahl, Yoichi Sugita, Alberto Vesperoni, Xavier Vives and participants at Stockholm School of Economics Lunch Seminar, European Workshop in Macroeconomics and Nordic Summer Symposium in Macroeconomics for helpful comments and suggestions. Financial support from the Jan Wallander and Tom Hedelius Foundation, and the Swedish Bank Research Foundation is gratefully acknowledged. All remaining errors are our own.

${ }^{\dagger}$ Email: taneli.makinen@hhs.se

‡Email: bjorn. ohl@hhs. se 


\section{Introduction}

Imperfect information has become to play a prominent role in business cycle theory. Recent contributions of Mankiw and Reis (2002), Woodford (2003) and Sims (2003) build on the foundations laid by Phelps (1969) and Lucas (1972). The idea spanning through these works is that imperfectly informed agents react slowly and gradually to changes in economic fundamentals. A criticism applying to the majority of imperfect information models is that the results hinge on exogeneously imposed information structures. On the other hand, in the analyses of Sims (2003), Reis (2006) and Maćkowiak and Wiederholt (2009), where agents are allowed to choose their information, two questions are not addressed. First, do agents' incentives to acquire information about aggregate conditions vary over the different phases of the business cycle. Second, how does the key feature in Lucas (1972), namely information contained in equilibrium prices, affect agents' information choices. To address these questions, we develop an equilibrium model of costly information acquisition and study agents' information choices over the business cycle. ${ }^{1}$

In our model, firms initially hold only imperfect information about the aggregate technology level that varies as the economy moves between booms and recessions. Prior to hiring labor in a perfectly competitive market, firms choose whether to acquire a fully revealing signal about the economy's true state at some fixed cost, and thus to learn the true technology level. An additional signal arises endogenously in the form of the labor market clearing wage. As the rational expectations equilibrium wage reflects firms' employment decisions, and ultimately the information they hold, it transmits information from firms that have bought the fully revealing signal to those that have not. In our model information acquisition is a strategic substitute. An individual firm's expected gain from acquiring the costly signal decreases as the fraction of informed firms increases. Demand for information and hence the fraction of informed firms differ across booms and recessions. When the economy has been in a boom in the previous period, and consequently firms enter the current period with an optimistic belief the fraction of informed firms is smaller than when the econ-

\footnotetext{
${ }^{1}$ Methodologically, the idea of information choice is not novel. See Veldkamp (2011) for a review of early and more recent models of information choice in macroeconomics and finance.
} 
omy has been in a recession and firms share a pessimistic belief. Information demand is countercyclical as, due to decreasing returns in production, learning the state of the economy benefits a firm more in a recession than in a boom. Decreasing returns implies that a marginal change in the firm's belief, inducing a marginal change in the firm's employment, affects the firm's output less when the firm's belief and consequently employment are high. However, information transmission via the price system moderates the cyclicality of the aggregate learning outcome. Learning from equilibrium wages lowers the incentive to become informed equally in booms and in recessions. This is due to uninformed firms being able to refine their information about the unknown state by observing the equilibrium wage. As a result of this information transmission, learning from equilibrium wages dampens information demand. Moreover, firms respond less to changes in the state of the economy than without learning from wages. Therefore, the price system, by discouraging information acquisition, stabilizes fluctuations. However, it can be welfare-enhancing to make information prohibitively costly to obtain as employment is less volatile when firms are more imperfectly informed.

Our paper is most closely related to the literature concerned with the implications of imperfect information for business cycles. Lucas (1972), formalizing Phelps (1969), studies an economy comprising physically separate markets, subject to aggregate monetary and real disturbances. Due to no communication between the markets, traders in each market are uncertain about the nature of the disturbance affecting the price they observe. Consequently, they attach a positive probability to any movement in the price originating from either a real or a monetary disturbance. Hence, real variables respond to unanticipated nominal shocks. Hahm (1987) augments Lucas (1972) by allowing traders to acquire information on aggregate variables and finds that the output-inflation tradeoff can vanish faster when increasing the variance of the monetary shock than without information acquisition. There are three important differences between Hahm (1987) and our analysis. First, in our environment, the real shock hitting the economy is persistent, allowing for state-dependence in information acquisition. Second, we study how learning from prices affects real aggregate fluctuations whereas Hahm (1987) is concerned with the inflation-output tradeoff. Third, our environment permits us establish uniqueness of the equi- 
librium price functional while Hahm (1987) finds an approximate equilibrium price functional ${ }^{2}$ by guess-and-verify.

The more recent imperfect information models of business cycles differ from our analysis in that they do not consider information transmission via the price system ${ }^{3}$. Woodford (2003), applying the idea of rational inattention proposed by Sims (2003), considers an imperfect information environment where firms pricing decisions are strategic complements. When firms receive private signals about aggregate demand, higher-order expectations enter pricing decisions as firms need to forecast each others' forecasts. Due to private signals being less informative about other firms' signals than about the aggregate state, the aggregate price level responds to a nominal disturbance only slowly and gradually. Mankiw and Reis (2002) obtain similar aggregate price level dynamics by assuming that firms obtain information about the state of the economy only sporadically. Reis (2006) shows that such stochastic updating is optimal when firms are allowed to acquire costly information. In Maćkowiak and Wiederholt (2009), on the other hand, rationally inattentive firms decide how much attention to allocate to idiosyncratic and to aggregate shocks. Due to idiosyncratic conditions being relatively more variable, firms find it optimal to attend more closely to idiosyncratic than aggregate conditions. We show that learning from prices constitutes an endogenous channel which discourages firms from acquiring information about aggregate shocks. Thus, our analysis suggests that in a rational inattention model à la Maćkowiak and Wiederholt (2009), introducing learning from prices would further dampen incentives to attend to aggregate conditions. More generally, our contribution to the literature on imperfect information and business cycles is to connect the earlier literature on the informational role of the price system with the more recent literature on information choice.

Our paper is also related to the literature concerned with procyclical learning as the source of asymmetric business cycles. Chalkley and Lee (1998) study a binary state, binary action model of capital utilization with imperfect information about the economy's state. In their model, due to risk aversion, investors require more precise information to choose the high than the low action, the lat-

\footnotetext{
${ }^{2}$ Markets clear only approximately in Hahm (1987).

${ }^{3}$ Lorenzoni (2009) is an exception but his analysis pertains to an exogenous information structure and concerns the effects of shocks to expectations.
} 
ter constructed to be the safer choice. Hence, noise investors, whose actions are independent of their belief about the economy's state, are more numerous relative to investors changing their action upon a state change in recessions than in booms. This, in turn, renders signals about the economy's state noisier in recessions than in booms. As a consequence, the dynamics of beliefs and aggregate activity are characterized by fast declines and slow recoveries. In Veldkamp (2005) asymmetric movements in lending rates are the result of more investment projects being undertaken in good than in bad times which generates a procyclical number of public signals about the unknown probability of a positive return. ${ }^{4}$ Similar to the idea of a larger number of signals in good than in bad times in Veldkamp (2005), the explanation for asymmetric movements in macroeconomic aggregates in Van Nieuwerburgh and Veldkamp (2006) relies on procyclical learning as a consequence of higher precision signals in booms than in recessions. In their model, an additional additive shock to aggregate technology ensures that the signal-to-noise ratio and thus learning is procyclical. All aforementioned papers, featuring procyclical learning as the source of asymmetric booms and recessions, share three model features that separate them from our analysis. First, agents in their models are passive learners whereas we allow them to choose whether to become informed, i.e. they are active learners. Second, we allow for an informational role of prices, that arises naturally in equilibrium with asymmetrically informed agents, a channel that is however absent in the three papers since agents are symmetrically informed. ${ }^{5}$ Third, public signals about aggregate activity are more informative in booms than in recession in their models. In Chalkley and Lee (1998) the high action, which firms choose when being sufficiently confident that the economy is in the good state, is chosen by few firms upon a state change, generating noisy information in a recession. Similarly, in Veldkamp (2005) the precision of the public signal moves procyclically as the number of investment projects is, by construction, greater in booms than in recessions. In Van Nieuwerburgh and Veldkamp (2006), in turn,

\footnotetext{
${ }^{4}$ Although the model in Veldkamp (2005) is primarily about asset markets instead of business cycles, gradual booms and prompt crashes due to procyclical learning make it relevant for our analysis.

${ }^{5}$ It is an important and well known result that with asymmetric information at least some agents will wish to reoptimize on their plans if learning from equilibrium prices is suppressed, see e.g. the discussions in Grossman (1981) and Laffont (1989), chapter 9.
} 
the variance of the aggregate statistic is smaller in booms than in recessions due to the combination of an additive and a multiplicative shock to aggregate technology. In our model, optimal information acquisition by firms gives rise to a countercyclical aggregate learning outcome. We contribute to the literature on learning and business cycles by examining information demand and showing that countercyclical learning can arise when information is costly to acquire and the price system transmits information. Thus, our paper can be viewed as complementing the analyses of information supply by Chalkley and Lee (1998), Veldkamp (2005) and Van Nieuwerburgh and Veldkamp (2006).

Moreover, we contribute to the literature on rational expectations equilibrium under asymmetric information. In the tradition of the seminal work of Grossman and Stiglitz (1980), the majority of models in this literature employ a CARA-Normal framework, where all equilibrium asset prices are equally informative about the unknown fundamental value. More intuitively, in our model different equilibrium wages differ in their informational content. More specifically, the highest and the lowest wages are more informative about the unknown state than intermediate wages. Moreover, in Grossman-Stiglitz type models the rational expectations equilibrium price functional is found by guess-and-verify, and uniqueness and attainability of equilibrium are not discussed. Our paper provides an alternative framework where existence of rational expectations equilibrium under asymmetric information can be established constructively. Furthermore, our framework allows us to prove uniqueness of equilibrium and to show how equilibrium can be attained through a tâtonnement-like process.

Finally, our paper relates to the empirical analysis by Coibion and Gorodnichenko (2010). They investigate survey data on forecasts of various macroeconomic variables and reject the hypothesis of full-information rational expectations. Moreover, their analysis suggests that this rejection stems from information rigidities, as measured by the predictability of forecast errors. Interestingly, as to the degree of information rigidity over the business cycle, recessions are characterized by a lower degree of information rigidity. Our analysis shows how such state dependence in expectation formation can arise when firms optimally acquire costly information. It is noteworthy that we obtain this result in an environment where firms' uncertainty about the state of the economy exhibits no exogenous cyclicality. 
The rest of the paper is organized as follows. In the next section, we lay out the model environment, describe the information structure and the ordering of events. Section 3 defines and analyzes equilibrium of the model. Here we show existence and uniqueness of rational expectations equilibrium with costly information acquisition. In Section 4 we present our main results: countercyclicality of both demand for information and the informativeness of the price system. Section 5 examines the role of learning from equilibrium wages, illustrates attainability of rational expectations equilibrium beliefs and discusses welfare. Section 6 concludes.

\section{Environment}

Time is discrete and indexed by $t \geq 0$. In each period the state of the economy is described by $z_{t} \in \mathscr{Z}=\{\underline{z}, \bar{z}\}, 0<\underline{z}<\bar{z}$, where $\underline{z}$ and $\bar{z}$ indicate a recession, and a boom respectively. The evolution of the state $z_{t}$ is governed by a Markov chain with time invariant and symmetric transition probabilities. The persistence of the process is denoted with $\rho \in\left(\frac{1}{2}, 1\right)$, where $\rho=\mathbb{P}\left(z_{t+1}=\bar{z} \mid z_{t}=\bar{z}\right)=\mathbb{P}\left(z_{t+1}=\right.$ $\left.\underline{z} \mid z_{t}=\underline{z}\right)$.

There is a measure-one continuum of ex ante identical firms, indexed by $i \in[0,1]$. Firm $i$ produces output $y_{i t}$ employing labor $h_{i t}$, taking as given the wage rate $w_{t}$. The firm's real profits in period $t$ are given by

$$
\Pi_{i t}=y_{i t}-w_{t} h_{i t} .
$$

The production technology of the firm exhibits diminishing returns to labor and is hit by an aggregate technology shock that depends on the state of the economy ${ }^{6}$

$$
y_{i t}=z_{t} \log \left(1+h_{i t}\right) .
$$

We close the model by introducing a representative household with preferences represented by the following period utility function defined over consumption and leisure

\footnotetext{
${ }^{6}$ The log-specification of firms' production technology in (2) and of the representative household's utility from leisure in (3) greatly simplifies equilibrium analysis, in that it allows us to derive a unique equilibrium wage functional that is linear in the exogenous shocks.
} 


$$
U\left(c_{t}, \ell_{t}\right)=c_{t}+\phi_{t} \log \left(\ell_{t}\right)
$$

where $\phi_{t} \in \Phi=[\underline{\phi}, \bar{\phi}], 0<\underline{\phi}<\bar{\phi}$, features a uniform i.i.d. taste shock that is independent of the state $z_{t}{ }^{7}$ The role of this aggregate supply shock, whose realization is known to the household but unknown to firms, is to introduce noise in the information revealed by the labor market clearing wage. ${ }^{8}$ As is well known from Grossman and Stiglitz (1976), in the absence of unobservable noise in labor supply, a competitive rational expectations equilibrium with costly information acquisition would fail to exist. Moreover, since our model addresses the information acquisition decision of competitive firms rather than of the representative household, we assume that consumption enters linearly in (3). Under that assumption, the household's labor supply schedule varies with the shock $\phi_{t}$ but remains unaffected by its belief about the state. The household's endowment of time is normalized to unity, that is $\ell_{t}+h_{t} \leq 1$. Finally, the representative household owns all firms and finances its consumption expenditures from labor income and aggregate profits. The budget constraint therefore reads

$$
c_{t} \leq w_{t} h_{t}+\int_{0}^{1} \Pi_{i t} \mathrm{~d} i .
$$

This concludes the description of the physical environment of the model. We now lay out the information structure of the economy and describe firms' learning rule together with the ordering of events.

\footnotetext{
${ }^{7}$ As we seek to analyze the microfoundations of learning over the business cycle, our choice of a state independent, uniformly distributed taste shock, together with the symmetric transition probabilities in the binary Markov chain, ensures that the source of any asymmetry does not hinge on the specification of the model's stochastic environment.

${ }^{8}$ The introduction of unobservable noise in labor supply in our model serves the same purpose as the random asset supply assumption in Grossman and Stiglitz (1980) and many closely related papers, for instance Hellwig (1980), Diamond and Verrecchia (1981), Verrecchia (1982), Admati (1985), and more recently in Ganguli and Yang (2009) and Van Nieuwerburgh and Veldkamp (2009).
} 


\section{Information structure, learning, and ordering of events}

In our model, the true state is a priori unknown to all firms by assumption. However, firms are allowed to acquire a costly signal about the state prior to choosing their profit maximizing employment level. In addition to this costly and exogenous signal, the labor market clearing wage will provide firms with another costless and endogenous signal about the current state. Whenever firms learn a new piece of information about the state, they update their belief in a Bayesian fashion. Since firms will hold different beliefs about the state within a single period, we distinguish between the following three stages.

Stage 1: Costly information acquisition. At the beginning of each period, before the opening of markets, the state $z_{t} \in \mathscr{Z}$ is drawn according to the Markov chain. Firms do not learn the true state. Instead, they enter the period with a common prior belief $\mu_{t}$ about the economy being in a boom, where $\mathbb{P}\left(z_{t}=\bar{z} \mid z_{t-1}\right)=\mu_{t}$ derives from the Markov chain. ${ }^{9}$ Firms choose individually and simultaneously whether to acquire a perfectly revealing signal $s_{t} \in \mathscr{S}=\{\underline{s}, \bar{s}\}$ about the state at a fixed $\operatorname{cost}^{10} \kappa>0$ that is equal across all firms and periods. Reselling purchased information is not permissible. Firms that pay $\kappa$ to observe signal $s_{t}$ update their belief to

$$
\tilde{\mu}_{t}^{I}= \begin{cases}1 & \text { if } s_{t}=\bar{s}, \\ 0 & \text { if } s_{t}=\underline{s},\end{cases}
$$

where the superscript $I$ identifies firms that become informed. Throughout the model $\lambda_{t} \in[0,1]$ denotes the fraction of firms that acquire the costly signal in stage 1 and hold the updated belief $\tilde{\mu}_{t}^{I}$. Accordingly, fraction $1-\lambda_{t}$ of firms choose not to observe signal $s_{t}$ and keep their initial prior belief $\mu_{t} .{ }^{11}$

\footnotetext{
${ }^{9}$ The fact that firms share a common prior is not an assumption. At the end of each period they learn the true state perfectly by observing their own output in (2) and exploiting their knowledge of the symmetric transition probability. This yields a common prior belief at the beginning of each period $t>0$.

${ }^{10}$ In Appendix B, we show how our results are affected when firms need to hire labor to acquire information.

${ }^{11}$ In the following, we will repeatedly refer to firms that acquire the costly signal as informed
} 
Stage 2: Learning from the equilibrium wage. The labor market opens and firms enter with their belief about the state from stage 1 . They maximize expected profits by choosing the optimal level of employment $h_{i t}$. Firms take as given the real wage rate $w_{t}$ and account for any information contained in the equilibrium wage about the state in their optimal labor demand. In particular, uninformed firms revise their stage 1 belief $\mu_{t}$ about the state to $\hat{\mu}_{t}^{U}$ upon observing the equilibrium real wage $w_{t}$. On the contrary, informed firms do not revise their belief $\tilde{\mu}_{t}^{I}$ from stage 1 , as the exogenous signal $s_{t}$ perfectly reveals the state of the economy. The representative household privately learns the realization of the taste shock $\phi_{t}$ and forms its labor supply $h_{t}^{S}$ to maximize expected period utility. The labor market clears.

Stage 3: End-of-period learning. Informed and uninformed firms produce outputs $y_{t}^{I}$ and $y_{t}^{U}$ according to their employment decisions from stage 2 , and given the realized technology level from stage 1 . The representative household chooses consumption, and the goods market clears. From observing their own output, uninformed firms can infer the true $z_{t}$ perfectly. Next period's common prior belief $\mu_{t+1}$ obtains from perfect knowledge of $z_{t}$ and the transition probabilities of the Markov chain

$$
\mu_{t+1}=\left\{\begin{array}{cc}
1-\rho & \text { if } z_{t}=\underline{z} \\
\rho & \text { if } z_{t}=\bar{z} .
\end{array}\right.
$$

For notational convenience we define the set of possible prior beliefs as $\mathscr{M}=\{1-\rho, \rho\}$. As a consequence of perfect end-of-period learning, information in the form of the costly signal has value only in the current period. The information acquisition problem in stage 1 is therefore purely static, as are the household's and firms' optimization problems in stages 2 and 3. This allows us to drop the time subscript from the next section on.

firms, and those firms refraining from costly information acquisition as uninformed firms. This is not entirely correct however, since the equilibrium wage contains noisy information about the state and thus allows firms that do not acquire the costly signal to become informed to some extent. However, no confusion should arise from our slight abuse of terminology. 


\section{Equilibrium}

We solve the model backwards, starting from equilibrium in the labor market in stage 2 , for a given fraction of informed firms. ${ }^{12}$ Then, we solve the stage 1 information acquisition problem taking as given the distribution of equilibrium outcomes in the labor market.

We solve for the labor market equilibrium using rational expectations equilibrium (REE) under asymmetric information, based on the pioneering work of Lucas (1972) and Green (1973). ${ }^{13}$ This equilibrium concept accounts for learning from prices by imposing a consistency requirement on equilibrium beliefs. Namely, beliefs are required to be in line with the information contained in the observed equilibrium wage. We show that in our model rational expectations equilibrium à la Lucas and Green exists and is unique.

\subsection{Labor market equilibrium}

Labor demand and supply schedules are found by solving the household's and firms' maximization problems. The household solves its static utility maximization in two steps. First, in stage 2, it chooses how much labor to supply for a given wage and realization of taste shock, $h^{S}(w, \phi)$. Then, in stage 3 , when labor income and profits are realized, it chooses consumption.

For $\lambda>0$, the equilibrium wage can reveal the signal $s$ the informed firms acquired. Hence, uninformed firms update their belief using the information that may be contained in the equilibrium wage they observe. Letting $\hat{\mu}^{U}(w, \mu)$ to stand for this updated belief, an uninformed firm's profit maximization problem reads

$$
\max _{h^{U} \geq 0}\left\{\hat{\mu}^{U}(w, \mu) \Pi\left(w, \bar{z}, h^{U}\right)+\left(1-\hat{\mu}^{U}(w, \mu)\right) \Pi\left(w, \underline{z}, h^{U}\right)\right\} .
$$

The resulting labor demand of an uninformed firm is denoted by $h^{U}\left(w, \hat{\mu}^{U}\right)$.

Informed firms maximize expected profits for a given wage, forming expec-

\footnotetext{
${ }^{12}$ Given that the household does not have access to a storage technology, goods market equilibrium in stage 3 is given by $\int y_{i} \mathrm{~d} i-\lambda \kappa=c$.

${ }^{13}$ For surveys on extensions of rational expectations equilibrium to asymmetric information see Radner (1979) and Grossman (1981).
} 
tations with belief $\hat{\mu}^{I}(w, \mu, s)^{14}$. That is, they solve

$$
\max _{h^{I} \geq 0}\left\{\hat{\mu}^{I}(w, \mu, s) \Pi\left(w, \bar{z}, h^{I}\right)+\left(1-\hat{\mu}^{I}(w, \mu, s)\right) \Pi\left(w, \underline{z}, h^{I}\right)\right\},
$$

yielding $h^{I}\left(w, \hat{\mu}^{I}\right)$, the labor demand of an informed firm. Having laid out the maximization problems of the agents, we can now define rational expectations equilibrium in the labor market.

Definition 1 (Rational expectations equilibrium in the labor market). Given a fraction of informed firms, $\lambda \in[0,1]$, rational expectations equilibrium in the labor market is a pair of demand schedules $h^{U}\left(w, \hat{\mu}^{U}\right)$ and $h^{I}\left(w, \hat{\mu}^{I}\right)$, a supply schedule $h^{S}(w, \phi)$ and a wage functional $\mathscr{W}_{\lambda}(\phi, \mu, s)$ such that for all $(\phi, \mu, s) \in$ $\Phi \times \mathscr{M} \times \mathfrak{S}$ and $w=\mathscr{W}_{\lambda}(\phi, \mu, s)$

1. $h^{U}\left(w, \hat{\mu}^{U}\right)$ and $h^{I}\left(w, \hat{\mu}^{I}\right)$ solve the uninformed and informed firm's profit maximization problem in (7) and (8), respectively;

2. beliefs are consistent with the realized wage $w$

$$
\begin{aligned}
\hat{\mu}^{U}(w, \mu) & =\mathbb{P}\left(z=\bar{z} \mid w=\mathscr{W}_{\lambda}(\phi, \mu, s), \mu\right) \\
\hat{\mu}^{I}(w, \mu, s) & =\mathbb{P}\left(z=\bar{z} \mid w=\mathscr{W}_{\lambda}(\phi, \mu, s), \mu, s\right)
\end{aligned}
$$

3. $h^{S}(w, \phi)$ solves the household's stage 2 problem;

4. labor market clears

$$
(1-\lambda) h^{U}\left(w, \hat{\mu}^{U}\right)+\lambda h^{I}\left(w, \hat{\mu}^{I}\right)=h^{S}(w, \phi) .
$$

The following proposition proves to be helpful in establishing existence and uniqueness of the labor market equilibrium. In particular, we show that the combination of uniform taste shocks and binary signals induces "all-ornothing" learning on the part of the uninformed firms.

Proposition 2 ("All-or-nothing" learning from REE wages). The set of rational expectations wages in the labor market can be partitioned into a set of wages which perfectly reveal the signal s of the informed firms and a set of wages which are perfectly uninformative about $s$.

\footnotetext{
${ }^{14}$ Informed firms do not learn anything new from the equilibrium wage, but we still write their belief as a function of the wage to indicate that their belief is equally required to be consistent with the equilibrium wage as formalized in (10). Similarly, the prior belief is redundant as an argument due to the fully revealing nature of the costly signal.
} 
Proof. Solving the representative household's labor supply problem yields

$$
h^{S}(w, \phi)= \begin{cases}1-\frac{\phi}{w} & \text { if } w>\phi \\ 0 & \text { otherwise }\end{cases}
$$

Firm $i$ 's labor demand, which solves its profit maximization problem is

$$
h_{i}(w, \mu)= \begin{cases}\frac{\mathbb{E}_{i}[z \mid w]}{w}-1 & \text { if } w<\mathbb{E}_{i}[z \mid w] \\ 0 & \text { otherwise }\end{cases}
$$

where $\mathbb{E}_{i}[z \mid w]$ denotes the expectation with respect to the equilibrium belief $\hat{\mu}_{i}(\cdot)$. For strictly positive equilibrium demands and supply ${ }^{15}$, market clearing in the labor market requires

$$
(1-\lambda) \mathbb{E}[z \mid w]+\lambda \mathbb{E}[z \mid w, s]=2 w-\phi .^{16}
$$

First, note that, due to the perfectly revealing nature of the signal, observing the equilibrium wage does not alter the belief of the informed firms. Thus, $\mathbb{E}[z \mid w, s]=\mathbb{E}[z \mid s]$.

To characterize the informativeness of wages, first suppose $s=\underline{s}$ and $\phi=$ $\phi^{\prime} \in \Phi$. Equilibrium wage $w=\mathscr{W}_{\lambda}\left(\phi^{\prime}, \mu, \underline{s}\right)$ is determined by

$$
(1-\lambda) \mathbb{E}[z \mid w]+\lambda \underline{z}=2 w-\phi^{\prime} .
$$

Note that if there does not exist $\phi^{\prime \prime} \in \Phi$ such that

$$
(1-\lambda) \mathbb{E}[z \mid w]+\lambda \bar{z}=2 w-\phi^{\prime \prime}
$$

then $w$ can only obtain when $s=\underline{s}$, hence perfectly revealing $s$. Otherwise, $w$ does not fully reveal $s$. Hence, for $w$ not to fully reveal $s$, taste shock $\phi^{\prime}$ and $\lambda$ have to be such that $\phi^{\prime}-\lambda(\bar{z}-\underline{z}) \geq \underline{\phi}$. Similarly, for $s=\bar{s}$ and $\phi=\phi^{\prime \prime} \in$ $\Phi$, if $\phi^{\prime \prime}+\lambda(\bar{z}-\underline{z}) \leq \bar{\phi}$, the resulting equilibrium wage does not fully reveal $s$. Otherwise, the uninformed can infer from the equilibrium wage that $s=\bar{s}$.

\footnotetext{
${ }^{15} \mathrm{~A}$ sufficient condition for strictly positive equilibrium quantities is $\bar{z}-\underline{z}<\underline{z}-\bar{\phi}$.

${ }^{16}$ Here and in the rest of this proof, we have suppressed the dependence of the expectation of $z$ on the prior belief $\mu$ for conciseness as none of the results depend on the prior belief.
} 
To show that not-fully-revealing wages are perfectly uninformative about $s$, let us derive the probability density function of $w$, conditional on $s$. One obtains

$$
f(w \mid s)=\frac{1}{\bar{\phi}-\underline{\phi}}\left|\frac{\partial \phi}{\partial w}\right| \text {. }
$$

Note from (15) and (16) that $\left|\frac{\partial \phi}{\partial w}\right|$ is not a function of $s$ for not-fully-revealing wages. Hence, from Bayes' rule we obtain the following ratio of posterior beliefs for all $\mu \in(0,1)$

$$
\begin{aligned}
\frac{\hat{\mu}^{U}(w, \mu)}{1-\hat{\mu}^{U}(w, \mu)} & =\frac{f(w \mid \bar{s})}{f(w \mid \underline{s})} \frac{\mu}{1-\mu} \\
& =\frac{\mu}{1-\mu}
\end{aligned}
$$

for $w$ which does not fully reveal $s$. Thus, not-fully-revealing wages are perfectly uninformative about $s$.

The above characterization allows us to construct the equilibrium wage functional, in contrast to Grossman-Stiglitz type models, which rely on guessand-verify. Moreover, our approach permits us not only to establish the existence of equilibrium but also its uniqueness.

Proposition 3 (Existence and uniqueness of REE). Rational expectations equilibrium in the labor market exists and is unique.

Proof. Note from the previous proof that whether an equilibrium wage $w$ perfectly reveals $s$ or is perfectly uninformative does not depend on the equilibrium belief of the uninformed, $\hat{\mu}^{U}(w, \mu)$. Thus, for each $(\phi, \mu, s)$ triplet: (1) the resulting equilibrium wage is either perfectly informative or completely uninformative and (2) the induced equilibrium belief of the uninformed is either the prior belief or the belief of the informed. Consequently, for each $(\phi, \mu, s)$ triplet there exists a unique rational expectations equilibrium wage, given by

$$
\begin{aligned}
& \mathscr{W}_{\lambda}(\phi, \mu, \underline{s})= \begin{cases}\frac{1}{2}[\phi+\underline{z}] & \text { if } \phi<\underline{\phi}+\lambda(\bar{z}-\underline{z}) \\
\frac{1}{2}[\phi+(1-\lambda) \mathbb{E}[z \mid \mu]+\lambda \underline{z}] & \text { otherwise, }\end{cases} \\
& \mathscr{W}_{\lambda}(\phi, \mu, \bar{s})= \begin{cases}\frac{1}{2}[\phi+(1-\lambda) \mathbb{E}[z \mid \mu]+\lambda \bar{z}] & \text { if } \phi \leq \bar{\phi}-\lambda(\bar{z}-\underline{z}) \\
\frac{1}{2}[\phi+\bar{z}] & \text { otherwise. }\end{cases}
\end{aligned}
$$




\subsection{Information acquisition equilibrium}

Equipped with the unique REE wage functional, we can solve a firm's information acquisition problem in stage 1. A firm will acquire information at cost $\kappa$ if the expected profit of an informed firm exceeds that of an uninformed firm by more than $\kappa$. Letting $G(\lambda)=\mathbb{E}\left[\Pi^{I}(w, \lambda) \mid \mu\right]-\kappa-\mathbb{E}\left[\Pi^{U}(w, \lambda) \mid \mu\right]^{17}$ to denote the expected gain from becoming informed, we define stage 1 equilibrium as follows.

Definition 4 (Information acquisition equilibrium). Information acquisition equilibrium is a fraction of informed firms $\lambda^{*}$ such that

$$
\lambda^{*}= \begin{cases}0 & \text { if } G(0)<0 \\ 1 & \text { if } G(1)>0 \\ \lambda^{*} \in[0,1] & \text { if } G\left(\lambda^{*}\right)=0 .\end{cases}
$$

A sufficient condition for the equilibrium fraction of informed firms to be unique is that the expected gain from becoming informed, $G(\lambda)$, is strictly decreasing in $\lambda$. We show below that information acquisition is a strategic substitute, i.e. the expected gain from becoming informed is indeed strictly decreasing in the fraction of informed firms.

\section{Demand for information and learning from prices}

We first establish strategic substitutability in information acquisition for all prior beliefs. Then, we turn to our main results, countercyclicality of demand for information and of the informativeness of the price system. We show that firms have a stronger incentive to acquire information when the economy has been in a recession in the previous period, and firms share a pessimistic belief about the economy being in a boom than when the economy has been in a boom and an optimistic belief prevails. As a consequence, the equilibrium fraction of informed firms is higher and the price system more informative when firms have a pessimistic belief than for an optimistic belief.

\footnotetext{
${ }^{17} \Pi(\cdot, \cdot)$ represents labor market equilibrium profit.
} 
Proposition 5 (Strategic substitutability in information acquisition). Given that for all $\lambda \in[0,1]$ there exists a non-degenerate interval of uninformative wages, the expected gain from becoming informed is strictly decreasing in the fraction of informed firms.

Proof. We want to show that the expected gain function satisfies $G^{\prime}(\lambda)<0$ for all $\lambda \in[0,1]$ given any $\mu \in(0,1)$. Given that uninformed and informed firms make identical choices for wages that fully reveal the signal $s$, the gain from becoming informed prior to opening of the labor market pertains to realizations of the signal and the taste shock which support uninformative wages. From (20) and (21) it follows that the lowest and highest uninformative wages, denoting them $\underline{w}$ and $\bar{w}$, respectively, are given by

$$
\begin{aligned}
& \underline{w}=\frac{1}{2} \underline{\phi}+\frac{1}{2}[(1-\lambda) \mathbb{E}[z \mid \mu]+\lambda \bar{z}] \\
& \bar{w}=\frac{1}{2} \bar{\phi}+\frac{1}{2}[(1-\lambda) \mathbb{E}[z \mid \mu]+\lambda \underline{z}] .
\end{aligned}
$$

Moreover, as $\mathbb{E}[z \mid w, \mu]=\mathbb{E}[z \mid \mu]$ for uninformative wages, we have from above that

$$
f(w \mid s)=\frac{2}{\bar{\phi}-\underline{\phi}} \quad \text { for } w \in[\underline{w}, \bar{w}] .
$$

Then, the prior-to-information-acquisition probability of observing an uninformative wage is

$$
\begin{aligned}
& \mu \int_{\underline{w}}^{\bar{w}} \frac{2}{\bar{\phi}-\underline{\phi}} \mathrm{d} w+(1-\mu) \int_{\underline{w}}^{\bar{w}} \frac{2}{\bar{\phi}-\underline{\phi}} \mathrm{d} w \\
& =\left[1-\frac{\lambda(\bar{z}-\underline{z})}{\bar{\phi}-\underline{\phi}}\right]
\end{aligned}
$$

for $\bar{\phi}-\underline{\phi}>\lambda(\bar{z}-\underline{z})$ and 0 otherwise.

Let us consider parameter values which ensure strictly positive equilibrium quantities. Then, uninformed and informed firms' profits, for optimal choices of labor as functions of $w$ and $z$, are

$$
\begin{aligned}
& \Pi^{U}(w, z)=z(\log (\mathbb{E}[z \mid w, \mu])-\log w)-(\mathbb{E}[z \mid w, \mu]-w), \\
& \Pi^{I}(w, z)=z(\log z-\log w)-(z-w),
\end{aligned}
$$


respectively. Expected gain from becoming informed is then found by integrating the difference between the profit of an informed and that of an uninformed firm over uninformative wages and accounting for the fixed cost of the signal:

$$
\begin{aligned}
G(\lambda)= & \mu \int_{\underline{w}}^{\bar{w}}\left(\Pi^{I}(w, \bar{z})-\Pi^{U}(w, \bar{z})\right) f(w \mid \bar{s}) \mathrm{d} w \\
& +(1-\mu) \int_{\underline{w}}^{\bar{w}}\left(\Pi^{I}(w, \underline{z})-\Pi^{U}(w, \underline{z})\right) f(w \mid \underline{s}) \mathrm{d} w-\kappa \\
= & {\left[1-\frac{\lambda(\bar{z}-\underline{z})}{\bar{\phi}-\underline{\phi}}\right][\mu \bar{z} \log \bar{z}+(1-\mu) \underline{z} \log \underline{z}-\mathbb{E}[z \mid \mu] \log (\mathbb{E}[z \mid \mu])]-\kappa, }
\end{aligned}
$$

for $\bar{\phi}-\underline{\phi}>\lambda(\bar{z}-\underline{z})$ and 0 otherwise. Note that the expected gain is equal to the probability of observing an uninformative wage multiplied by the difference in expected profits for a given wage, which is independent of $\lambda$ and strictly positive for $\mu \in(0,1)$ by Jensen's inequality. Under the parameter restriction $\bar{\phi}-\underline{\phi}>\bar{z}-\underline{z}$ the existence of a non-degenerate interval of uninformative wages is guaranteed for all $\lambda \in[0,1]$ and we have $G^{\prime}(\lambda)<0$ as was to be shown.

In our model, strategic substitutability in information acquisition arises from an information externality due to rational expectations equilibrium wages transmitting information, similar to Grossman and Stiglitz (1980). As more firms acquire the costly signal and become informed about the economy's state, the price system becomes more informative as measured by the probability of observing an informative wage. As a consequence, an individual firm's incentive to acquire the costly signal is reduced. Hence, the expected gain of becoming informed decreases in the fraction of informed firms.

We now turn to our two main results, countercyclicality of information demand and of the informativeness of the price system, both of which constitute novel findings in the literature on imperfect information and business cycles. These results are stated in the following proposition and its corollary.

Proposition 6 (Countercyclical information demand). Suppose the probability of observing an uninformative wage is strictly positive. Then, the expected gain from becoming informed for a given fraction of informed firms is higher for the low prior belief $1-\rho$ than for the high prior belief $\rho$. 
Proof. Note from (27) that the probability of observing an uninformative wage is independent of $\mu$. Hence, to show the countercyclicality of expected gain with respect to the prior belief $\mu$, it suffices to show that

$$
g(\mu):=\mu \bar{z} \log \bar{z}+(1-\mu) \underline{z} \log \underline{z}-\mathbb{E}[z \mid \mu] \log (\mathbb{E}[z \mid \mu])
$$

is such that $g(1-\rho)>g(\rho)$ for all $\rho \in\left(\frac{1}{2}, 1\right)$. Defining $f(\rho):=g(1-\rho)-g(\rho)$, we have $f\left(\frac{1}{2}\right)=f(1)=0$. Moreover,

$$
f^{\prime \prime}(\rho)=(\bar{z}-\underline{z})^{2}\left(\frac{1}{\rho \bar{z}+(1-\rho) \underline{z}}-\frac{1}{(1-\rho) \bar{z}+\rho \underline{z}}\right)<0
$$

for $\rho \in\left(\frac{1}{2}, 1\right)$. Hence, $g(1-\rho)>g(\rho)$ for all $\rho \in\left(\frac{1}{2}, 1\right)$.

Countercyclical demand for information arises from production technology exhibiting decreasing returns to labor and a firm's demand for labor being linear in its belief. ${ }^{18}$ Consequently, a marginal change in the firm's employment, induced by a marginal change in the firm's belief, will change its output less when the firm's belief and employment are high than when they are low. Thus, the firm is less willing to acquire the perfectly revealing signal when the prior belief is high as a revision in the firm's belief will have a smaller effect on output than when the prior belief is low.

Countercyclical information demand implies that, given $\kappa$ is such that we have an interior solution for $\lambda^{*}$, the fraction of informed firms is higher for the pessimistic belief than for the optimistic belief. This, in turn, implies that the probability of observing a perfectly revealing wage is higher for the low prior belief than for the high prior belief. As equilibrium wages are either perfectly revealing or perfectly uninformative, a straightforward measure of the informativeness of the price system is the probability of observing an informative wage. Hence, from the preceding proposition we obtain the following.

Corollary 7 (Countercyclical informativeness of the price system). Given that the cost of the signal is such that an interior solution for the equilibrium fraction of informed firms obtains, the price system is more informative when the low prior belief $1-\rho$ prevails than when the high prior belief $\rho$ prevails.

\footnotetext{
${ }^{18}$ Appendix A shows that under a more general specification of technology there is an additional force acting to render firms' demand for information countercyclical.
} 
Proof. From $g(1-\rho)>g(\rho)$ as shown in the proof of Proposition 6 and from Definition 4 , for $\kappa$ such that $\lambda^{*} \in(0,1)$, the equilibrium fraction of informed firms, $\lambda^{*}$ is higher for the pessimistic belief than for the optimistic belief. Then, by equation (27), the probability of observing an informative wage is higher when the prior belief is $1-\rho$ than for prior belief of $\rho$.

\section{Discussion}

In this section we first delve deeper into the role of learning from equilibrium wages and examine how it affects the countercyclicality of information demand established in Proposition 6. To study how firms' incentives to acquire information will change if learning from wages is suppressed, we consider Walrasian equilibrium in the labor market, which does not require firms' beliefs to be consistent with the observed wage ${ }^{19}$. When the informational role of wages is suppressed, a firm's incentives for acquiring information are no more affected by other firms' information acquisition decisions. Consequently, without learning from wages either all firms are informed or no firm is informed. Therefore, learning from wages moderates the cyclicality in incentives to acquire information.

After having examined Walrasian equilibrium, a solution concept with offequilibrium beliefs, we turn to the question of how firms may come to hold rational expectations equilibrium beliefs. To shed light on attainability of equilibrium beliefs, we consider an equilibrium concept, introduced by Kobayashi (1977) and Jordan $(1982,1985)$, where a sequence of wages is observed and used to update beliefs in a Bayesian fashion. We find that beliefs and wages under this alternative equilibrium concept converge to their counterparts in REE after observing a single Walrasian equilibrium wage.

Finally, we conduct a welfare analysis to address efficiency of the decentralized economy with regards to information acquisition. That is, whether there is too little or too much information acquisition from the perspective of the repre-

\footnotetext{
${ }^{19}$ We follow Grossman (1981) in referring to the solution concept which does not require beliefs to be in line with the observed wage as Walrasian equilibrium. However, note that this solution concept does not constitute an equilibrium as firms have an incentive to reoptimize on their plans on observing the wage.
} 
sentative household. We first illustrate that the level of information acquisition in the decentralized economy is not, in general, efficient. Then, we show that, if a benevolent social planner could choose the cost of acquiring information, she would choose the highest feasible cost for some parameterizations.

\subsection{Role of learning from wages}

Let us begin by defining a solution concept which disregards learning from wages, namely Walrasian equilibrium.

Definition 8 (Walrasian equilibrium in the labor market). Given a fraction of informed firms, $\lambda \in[0,1]$, Walrasian equilibrium in the labor market is a pair of demand schedules $h^{U}\left(w, \breve{\mu}^{U}\right)$ and $h^{I}\left(w, \breve{\mu}^{I}\right)$, a supply schedule $h^{S}(w, \phi)$ and a wage functional $\breve{W}_{\lambda}\left(\phi, \breve{\mu}^{U}, \breve{\mu}^{I}\right)$ such that for all $\left(\phi, \breve{\mu}^{U}, \breve{\mu}^{I}\right) \in \Psi \times[0,1]^{2}$ and $w=$ $\breve{W}_{\lambda}\left(\phi, \breve{\mu}^{U}, \breve{\mu}^{I}\right)$

1. $h^{U}\left(w, \breve{\mu}^{U}\right)$ and $h^{U}\left(w, \breve{\mu}^{I}\right)$ solve

$$
\begin{aligned}
& \max _{h^{U} \geq 0}\left\{\breve{\mu}^{U} \Pi\left(w, \bar{z}, h^{U}\right)+\left(1-\breve{\mu}^{U}\right) \Pi\left(w, \underline{z}, h^{U}\right)\right\}, \\
& \max _{h^{I} \geq 0}\left\{\breve{\mu}^{I} \Pi\left(w, \bar{z}, h^{I}\right)+\left(1-\breve{\mu}^{I}\right) \Pi\left(w, \underline{z}, h^{I}\right)\right\},
\end{aligned}
$$

respectively;

2. $h^{S}(w, \phi)$ solves the household's stage 2 problem;

3. labor market clears

$$
\lambda h^{I}\left(w, \breve{\mu}^{I}\right)+(1-\lambda) h^{U}\left(w, \breve{\mu}^{U}\right)=h^{S}(w, \phi) .
$$

To find the expected gain from becoming informed when the stage 2 labor market equilibrium is Walrasian, note from (28) and (29) that the gain from becoming informed at any wage $w$ is not a function of $w$. Moreover, as there is no learning from wages, the expected gain from becoming informed is found by integrating over all possible Walrasian equilibrium wages and accounting for the cost of the signal

$$
\breve{G}=\mu \bar{z} \log \bar{z}+(1-\mu) \underline{z} \log \underline{z}-\mathbb{E}[z] \log (\mathbb{E}[z])-\kappa .
$$


Comparison of (30) and (36) reveals that the expected gain from becoming informed with learning from wages is equal to the gain when learning from wages is suppressed, scaled by the probability of observing an uninformative wage. Therefore, for $\kappa$ such that $\lambda^{*}$ is strictly positive, learning from equilibrium wages moderates incentives to acquire costly information. Moreover, without learning from wages, depending on whether $\breve{G}$ is negative or positive, the fraction of informed firms is either 0 or 1 . Thus, when equilibrium in the labor market is Walrasian, there exists $\kappa>0$ such that all firms are informed when the pessimistic belief prevails and no firm is informed when the public belief is optimistic. On the other hand, when learning from wages is allowed, the fraction of informed firms differs less across the two possible public beliefs. Thus, learning from wages moderates the cyclicality of information demand. This is due the labor market equilibrium wage serving as a costless signal about the unknown state, lowering the incentive to become informed equally in booms and in recessions.

\subsection{Attainability of REE beliefs}

Our sequence of markets equilibrium, adopted from Jordan (1985), formalizes what Vives (2008) refers to as information tâtonnement ${ }^{20}$. Firms express their demand for labor, based only on their private information at the time. Their demand schedules are aggregated and the notional ${ }^{21}$ market clearing wage announced. Firms then update their beliefs using any information that may be contained in the announced notional market clearing wage and adjust their demand schedules to reflect their updated beliefs. Updated demand schedules are collected and a new notional market clearing wage announced. This process is allowed to continue until all firms no more wish to adjust their demand schedule, which requires that firms' beliefs are not altered by the last market clearing wage. Our sequence of markets equilibrium builds on Walrasian equilibrium as follows.

Definition 9 (Sequence of markets equilibrium). Given a fraction of informed

\footnotetext{
${ }^{20}$ See Vives (2008), pp. 334-335.

${ }^{21}$ Notional refers to the wage that would clear the market for the given supply and the current demands. However, trades are not yet executed.
} 
firms, $\lambda \in[0,1]$, sequence of markets equilibrium is a sequence of pairs of demand schedules $\left\{h_{n}^{U}\left(w, \breve{\mu}_{n}^{U}\right), h_{n}^{I}\left(w, \breve{\mu}_{n}^{I}\right)\right\}$, a supply schedule $h^{S}(w, \phi)$ and a wage functional $\breve{W}_{\lambda}\left(\phi, \breve{\mu}_{n}^{U}, \breve{\mu}_{n}^{I}\right)$ such that $\forall n \in \mathbb{Z}_{+}$

1. $h_{n}^{U}\left(w, \breve{\mu}_{n}^{U}\right), h_{n}^{I}\left(w, \breve{\mu}_{n}^{I}\right), h^{S}(w, \phi)$ and $\breve{\mathscr{W}}_{\lambda}\left(\phi, \breve{\mu}_{n}^{U}, \breve{\mu}_{n}^{I}\right)$ constitute a Walrasian equilibrium;

2. $\breve{\mu}_{0}^{U}=\tilde{\mu}^{U}(\mu), \breve{\mu}_{0}^{I}=\tilde{\mu}^{I}(\mu, s)$ and

$$
\begin{aligned}
& \breve{\mu}_{n+1}^{U}=\mathbb{P}\left(z=\bar{z} \mid \breve{w}_{n}=\breve{\mathscr{W}}_{\lambda}\left(\phi, \breve{\mu}_{n}^{U}, \breve{\mu}_{n}^{I}\right), \breve{\mu}_{n}^{U}\right), \\
& \breve{\mu}_{n+1}^{I}=\mathbb{P}\left(z=\bar{z} \mid \breve{w}_{n}=\breve{\mathscr{W}}_{\lambda}\left(\phi, \breve{\mu}_{n}^{U}, \breve{\mu}_{n}^{I}\right), \breve{\mu}_{n}^{I}\right) ;
\end{aligned}
$$

3. $\lim _{n \rightarrow \infty} \breve{\mu}_{n}^{U}=\breve{\mu}^{U}$ and $\lim _{n \rightarrow \infty} \breve{\mu}_{n}^{I}=\breve{\mu}^{I}$.

In our model, rational expectations equilibrium beliefs are attainable via observing and processing the information contained in a sequence of notional Walrasian market clearing wages. This is formalized in the following proposition.

Proposition 10 (Attainability of REE beliefs). Sequence of markets equilibrium beliefs and wages converge to their rational expectations equilibrium counterparts after observing a single Walrasian equilibrium wage.

Proof. Note from Proposition 2 that whether a REE wage is perfectly informative or perfectly uninformative does not depend on the belief of the uninformed, $\hat{\mu}^{U}$, but only on $\phi$ and $s$. Hence, in the first step of the sequence of Walrasian markets, when the uninformed use only their prior belief to formulate their demands, the informativeness of $\breve{w}_{0}$ is determined by exactly the same conditions on $\phi$ as the informativeness of REE wages. For the same reason, the uninformed cannot learn anything more from $\breve{w}_{1}$. Hence, the sequence of Walrasian markets wage functional satisfies $\breve{\mathscr{W}}_{\lambda}\left(\phi, \breve{\mu}_{1}^{U}, \breve{\mu}_{1}^{I}\right)=\breve{\mathscr{W}}_{\lambda}\left(\phi, \breve{\mu}^{U}, \breve{\mu}^{I}\right)=\mathscr{W}(\phi, \mu, s)$. That is, Walrasian equilibrium wages in the first step contain the same information as rational expectations equilibrium wages.

\subsection{Welfare}

To address the efficiency of information acquisition in the decentralized economy, we examine how the expected utility of the representative household varies with the fraction of informed firms. Figure 1 illustrates this relationship. 

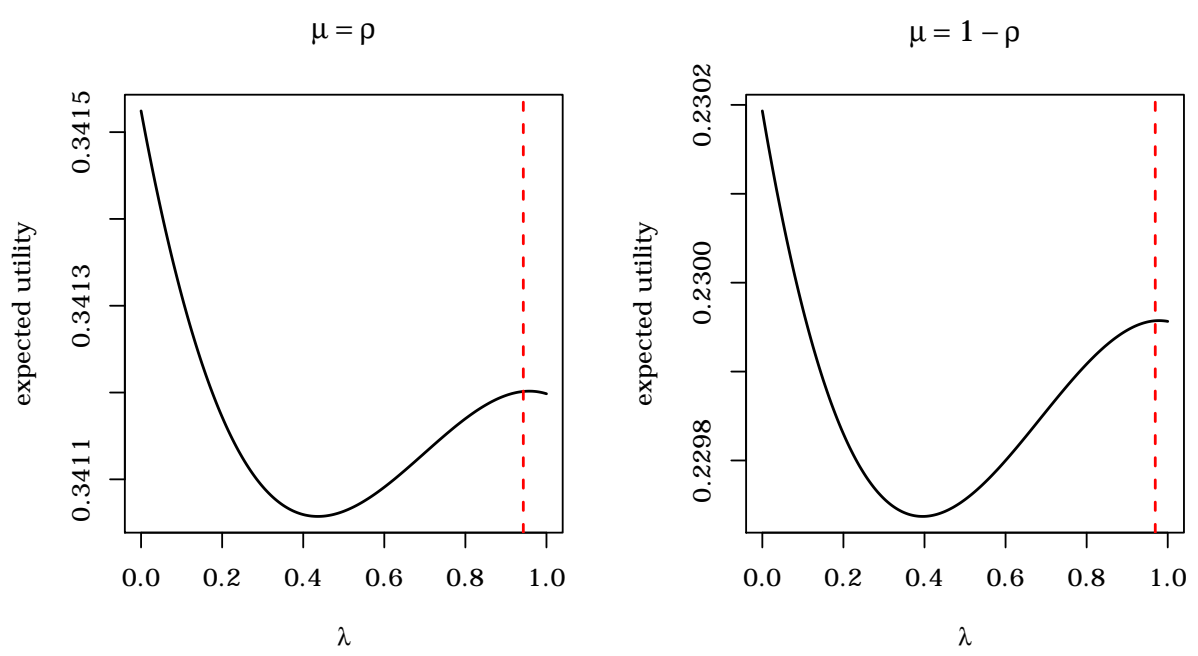

Figure 1: Expected utility as a function of the fraction of informed firms for $\underline{z}=1$, $\bar{z}=1.3, \underline{\phi}=0.1, \bar{\phi}=0.5, \rho=0.9$ and $\kappa=0.001$. The dashed line indicates the equilibrium fraction of informed firm in the decentralized economy.

Crucially, Figure 1 reveals that information acquisition is not, in general, efficient in the decentralized economy. For both prior beliefs the equilibrium fraction of informed firms is above 0.9 whereas welfare is maximized when no firm is informed. To understand the sources of this inefficiency note that when a firm decides whether to become informed it only weighs the private benefit from being able to operate at the optimal scale against the cost of acquiring the signal. A benevolent social planner, on the other hand, considers three additional effects of information acquisition. First, the price system becomes more informative, increasing the probability that the uninformed firms produce at the same scale as the informed firms. Due to decreasing returns, for a given wage, an uninformed firm produces more in expectation than an informed firm. Thus, a more informative price system, by altering firms' labor demand, exerts a downward pressure on expected aggregate output. This acts to make the socially optimal level of information acquisition lower than that in the decentralized economy. Second, the volatility of the equilibrium wage increases as aggregate labor demand varies more strongly with the state of the economy. Consequently, the volatility of labor supply increases, lowering the expected utility of the represen- 


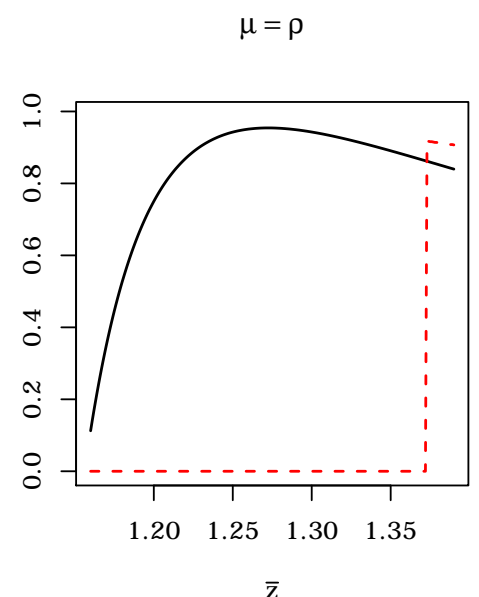

$\bar{Z}$

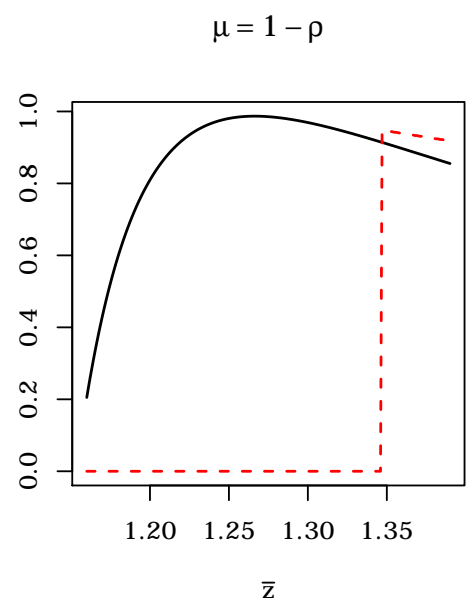

Figure 2: Equilibrium fraction of informed firms $\lambda^{*}$ and the socially optimal fraction of informed firms $\tilde{\lambda}$ for $\underline{z}=1, \underline{\phi}=0.1, \bar{\phi}=0.5, \rho=0.9$ and $\kappa=0.001$.

tative household. Thus, the planner has an additional reason for fewer firms to acquire information than in the decentralized economy. Third, the equilibrium wage more accurately reflects labor productivity. As a result, labor supplied by the representative household is closer to the optimum under full information. Moreover, expected aggregate output tends to increase as the equilibrium wage is less distorted by the uninformed firms. Therefore, the third effect advocates more firms to become informed than in the decentralized economy. Returning to Figure 1, as more firms acquire information, welfare initially decreases due to the first and second effects but later increases due to the third effect.

In finding the optimal level of information acquisition, the social planner faces a trade-off between efficiency and volatility. Figure 2 shows how there can also be less information acquisition in the decentralized economy than what is socially optimal. When productivity in the high state increases in Figure 2, the optimal level of information acquisition eventually exceeds that in the decentralized economy as the benefit from production efficiency more than compensates for higher wage volatility.

Given that information acquisition in the decentralized economy is not efficient, the question arises how welfare could be improved. Suppose that a policy- 

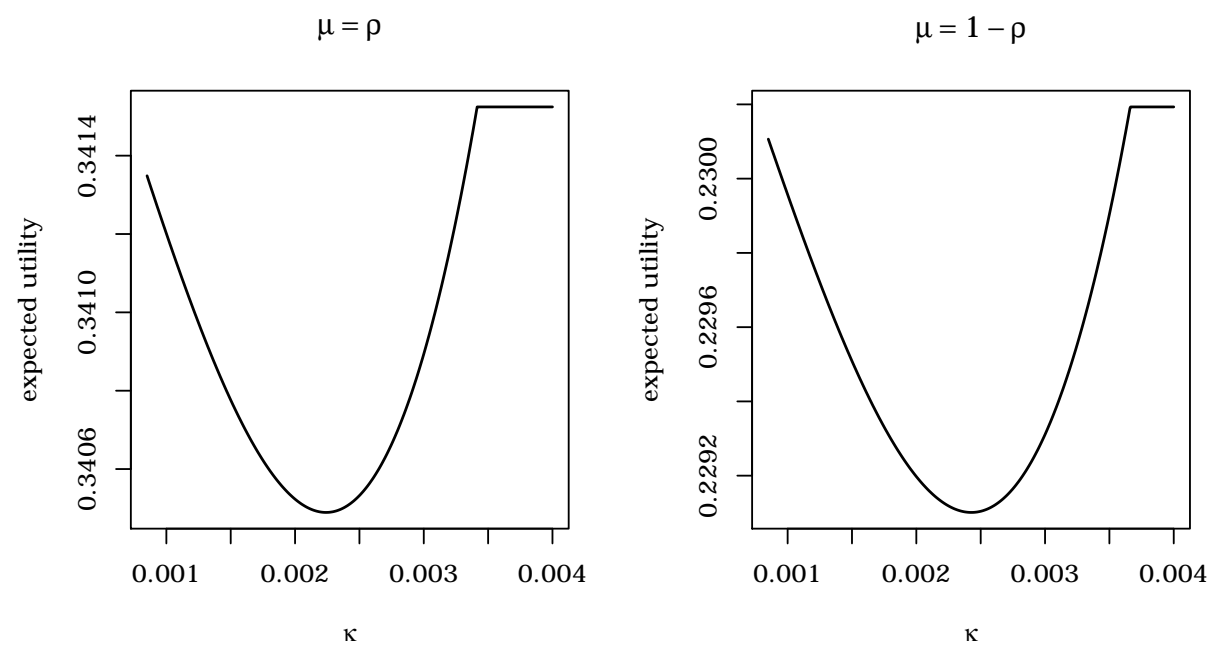

Figure 3: Expected utility as a function of the cost of acquiring information for $\underline{z}=1, \bar{z}=1.3, \underline{\phi}=0.1, \bar{\phi}=0.5$ and $\rho=0.9$.

maker can choose the cost of acquiring information in an interval with a strictly positive lower bound. Then, to minimize the volatility of wages and to avoid resources being used for information acquisition, the policy-maker may want to choose the cost to be high enough such that firms optimally choose to acquire no information. An example of such an economy is given in Figure 3, showing how welfare varies with the cost of becoming informed. One can think of the cost as measuring the difficulty of finding information about the economy. In that sense, when the policy-maker chooses a high cost of information acquisition, she opts for low level of transparency.

\section{Conclusion}

We have investigated the implications of firms' acquisition of costly information and the transmission of information via the price system on business cycle dynamics by addressing two so far unanswered questions. Namely, whether firms have a stronger incentive to acquire information in booms or in recessions and how learning from prices contributes to aggregate learning outcomes. We find that in a model environment featuring no exogenous source of asymmetry firms' 
information demand is countercyclical. This is due to decreasing returns in production, implying that a marginal change in a firm's belief, inducing a marginal change in the firm's employment, affects the firm's output less when the firm's belief and employment are high. We establish a crucial role for learning from equilibrium prices. The price system, by transmitting information from the informed to the uninformed, dampens information demand. Therefore, the aggregate learning outcome is less cyclical when firms exploit information contained in equilibrium wages than when learning from wages is not taken into consideration. Moreover, firms respond less to changes in the state of the economy than without learning from wages. Hence, the price system, by discouraging information acquisition, acts to stabilize fluctuations.

A welfare analysis of information acquisition in the decentralized economy reveals that making information prohibitively costly to obtain can be welfareenhancing. This is at first sight surprising as information, in improving efficiency of production, is socially beneficial. However, when more firms acquire information, employment becomes more volatile, which lowers welfare. Thus, reducing transparency can increase social welfare. 


\section{References}

Admati, A. R. (1985): "A Noisy Rational Expectations Equilibrium for Multi-Asset Securities Markets," Econometrica, 53(3), 629-657.

Chalkley, M., and I. H. Lee (1998): "Learning and Asymmetric Business Cycles," Review of Economic Dynamics, 1(3), 623-645.

Coibion, O., and Y. Gorodnichenko (2010): "Information Rigidity and the Expectations Formation Process: A Simple Framework and New Facts," NBER Working Paper No. 16537, NBER.

Diamond, D. W., and R. E. Verrecchia (1981): "Information Aggregation in a Noisy Rational Expectations Economy," Journal of Financial Economics, 9(3), 221-235.

Ganguli, J. V., And L. YANG (2009): “Complementarities, Multiplicity, and Supply Information," Journal of the European Economic Association, 7(1), 90-115.

Green, J. R. (1973): “Information, Efficiency and Equilibrium,” Harvard University Discussion Paper 284, Harvard Institute of Economic Research.

Grossman, S. J. (1981): "An Introduction to the Theory of Rational Expectations under Asymmetric Information," Review of Economic Studies, 48(4), 541-559.

Grossman, S. J., and J. E. Stiglitz (1976): "Information and Competitive Price Systems," American Economic Review, 66(2), 246-253.

(1980): “On the Impossibility of Informationally Efficient Markets," American Economic Review, 70(3), 393-408.

НАнм, S. (1987): "Information Acquisition in an Incomplete Information Model of Business Cycle," Journal of Monetary Economics, 20(1), 123-140.

Hellwig, M. F. (1980): “On the Aggregation of Information in Competitive Markets," Journal of Economic Theory, 22(3), 477-498.

JoRDAN, J. S. (1982): “A Dynamic Model of Expectations Equilibrium," Journal of Economic Theory, 28(2), 235-254. 
(1985): "Learning Rational Expectations: The Finite State Case," Journal of Economic Theory, 36(2), 257-276.

Kobayashi, T. (1977): “A Convergence Theorem on Rational Expectations Equilibrium With Price Information," Working Paper No. 79, Economic Series, Institute for Mathematical Studies in the Social Sciences, Stanford University.

LAFFONT, J. J. (1989): The Economics of Uncertainty and Information. MIT Press, Cambridge, USA.

Lorenzoni, G. (2009): “A Theory of Demand Shocks," American Economic Review, 99(5), 2050-2084.

LuCAS, R. E. J. (1972): "Expectations and the Neutrality of Money," Journal of Economic Theory, 4(2), 103-124.

Maćkowiak, B., and M. Wiederholt (2009): "Optimal Sticky Prices under Rational Inattention," American Economic Review, 99(3), 769-803.

Mankiw, E. G., and R. Reis (2002): "Sticky Information versus Sticky Prices: A Proposal to Replace the New Keynesian Phillips Curve," Quarterly Journal of Economics, 117(4), 1295-1328.

Phelps, E. S. (1969): “The New Microeconomics in Inflation and Employment Theory," American Economic Review, 59(2), 147-160.

RAdner, R. (1979): "Rational Expectations Equilibrium: Generic Existence and the Information Revealed by Prices," Econometrica, 47(3), 655-678.

ReIs, R. (2006): “Inattentive Producers,” Review of Economic Studies, 73(3), 793821.

Sims, C. A. (2003): “Implications of Rational Inattention," Journal of Monetary Economics, 50(3), 665-690.

Van Nieuwerburgh, S., and L. Veldkamp (2006): "Learning Asymmetries in Real Business Cycles,” Journal of Monetary Economics, 53(4), 753-772.

(2009): "Information Immobility and the Home Bias Puzzle," The Journal of Finance, 64(3), 1187-1215. 
VeldKamp, L. (2005): “Slow Boom, Sudden Crash,” Journal of Economic Theory, 124(2), 230-257.

(2011): Information Choice in Macroeconomics and Finance. Princeton University Press, Princeton, New Jersey, USA.

VerReCCHIA, R. E. (1982): "Information Acquisition in a Noisy Rational Expectations Economy," Econometrica, 50(6), 1415-1430.

Vives, X. (2008): Information and Learning in Markets: The Impact of Market Microstructure. Princeton University Press, Princeton, New Jersey, USA.

Woodford, M. (2003): "Imperfect Common Knowledge and the Effects of Monetary Policy," in Knowledge, Information, and Expectations in Modern Macroeconomics: In Honor of Edmund S. Phelps, ed. by P. Aghion, R. Frydman, J. Stiglitz, and M. Woodford, pp. 25-58. Princeton University Press, Princeton, New Jersey, USA. 


\section{A More general production technology}

In this appendix, we study firms' information demand under a more general specification of production technology. Namely, firm $i$ 's output when it employs $h_{i}$ units of labor is given by

$$
y_{i}=z h_{i}^{\alpha},
$$

where $0<\alpha<1$. We first consider a fixed wage to be able to compare the resulting information demand to that under the log-specification, when the expected wage does not enter the expected gain from becoming informed. We obtain the following.

Proposition 11 (Information demand for a fixed wage). For a fixed wage, a firm's information demand is countercyclical, i.e. the expected gain from becoming informed is higher for the low prior belief $1-\rho$ than for the high prior belief $\rho$, when $\alpha<\frac{1}{2}$, acyclical when $\alpha=\frac{1}{2}$ and procyclical when $\alpha>\frac{1}{2}$.

Proof. Uninformed and informed firms' profits, for profit-maximizing choices of labor, as functions of $w$ and $z$ are

$$
\begin{aligned}
& \Pi^{U}(w, z)=\left(\frac{\alpha}{w}\right)^{\frac{\alpha}{1-\alpha}}\left[z(\mathbb{E}[z \mid \mu])^{\frac{\alpha}{1-\alpha}}-\alpha(\mathbb{E}[z \mid \mu])^{\frac{1}{1-\alpha}}\right], \\
& \Pi^{I}(w, z)=\left(\frac{\alpha}{w}\right)^{\frac{\alpha}{1-\alpha}}(1-\alpha) z^{\frac{1}{1-\alpha}},
\end{aligned}
$$

respectively. Consequently, the expected gain from becoming informed is

$$
\bar{G}=\left(\frac{\alpha}{w}\right)^{\frac{\alpha}{1-\alpha}}(1-\alpha)\left[\mu \bar{z}^{\frac{1}{1-\alpha}}+(1-\mu) \underline{z}^{\frac{1}{1-\alpha}}-(\mathbb{E}[z \mid \mu])^{\frac{1}{1-\alpha}}\right] .
$$

Firms have countercyclical demand for information when

$$
\bar{g}(\mu):=\mu \bar{z}^{\frac{1}{1-\alpha}}+(1-\mu) \underline{z}^{\frac{1}{1-\alpha}}-(\mathbb{E}[z \mid \mu])^{\frac{1}{1-\alpha}}
$$

is such that $\bar{g}(1-\rho)>\bar{g}(\rho)$ for all $\rho \in\left(\frac{1}{2}, 1\right)$. When the converse holds, i.e. $\bar{g}(\rho)>\bar{g}(1-\rho)$, firms have procyclical demand for information. Following the proof of Proposition 6 , let $\bar{f}(\rho):=\bar{g}(1-\rho)-\bar{g}(\rho)$ and note that $\bar{f}\left(\frac{1}{2}\right)=\bar{f}(1)=0$. As

$$
\bar{f}^{\prime \prime}(\rho)=\alpha\left(\frac{\bar{z}-\underline{z}}{1-\alpha}\right)^{2}\left\{[\rho \bar{z}+(1-\rho) \underline{z}]^{\frac{2 \alpha-1}{1-\alpha}}-[(1-\rho) \bar{z}+\rho \underline{z}]^{\frac{2 \alpha-1}{1-\alpha}}\right\}
$$

$\bar{g}(1-\rho)>\bar{g}(\rho)$ for $\alpha<\frac{1}{2}, \bar{g}(1-\rho)=\bar{g}(\rho)$ for $\alpha=\frac{1}{2}$ and $\bar{g}(\rho)>\bar{g}(1-\rho)$ for $\alpha>\frac{1}{2}$. 
The cyclicality of a firm's information demand depends both on the degree of decreasing returns in production and on the responsiveness of the firm's employment to its belief about the state of the economy. Under the production technology considered here, a firm's employment is convex in its belief about the state. Thus, a change in the firm's belief changes its employment more when the belief is high than when it is low. Moreover, when $\alpha$ approaches 1 from below, the production technology exhibits less decreasing returns to labor. Consequently, for high enough $\alpha$, a firm's output responds more to a marginal change in its belief in a boom, when the prior belief is high, than in a recession, when the low prior belief prevails. Thus, procyclical information demand obtains for $\alpha>\frac{1}{2}$. For $\alpha<\frac{1}{2}$, the production technology exhibits sufficiently decreasing returns to labor such that, even though a firm's employment is convex in its belief, the effect of a marginal change in the belief on output is smaller when the belief is high. Therefore, in this case, information demand is countercyclical.

Next, consider how information demand would be affected when the wage varies to clear the labor market. The expected gain from becoming informed for a fixed wage (A-4) reveals that information demand is decreasing in the wage. That is, firms are more willing to acquire information when the wage is low than when it is high. Moreover, note that the expected wage is lower in a recession than in a boom. Thus, information demand is more countercyclical when the wage is determined by labor market clearing than when the wage is fixed. That is, firms have a stronger incentive to acquire information when the wage is suppressed by a pessimistic belief about the state of the economy and expanding employment entails a lower cost. This analysis shows that the log-specification, under which a firm's employment is linear in its belief, is less conducive to countercyclical information demand than the more general production technology considered here as the effect of a lower expected wage in a recession than in a boom is not present under the log-specification. 


\section{B Endogenous cost of acquiring information}

Let us see how our results are affected when firms need to hire labor, instead of paying a fixed cost, to acquire information. Suppose that to acquire the perfectly revealing signal a firm needs to hire $\chi$ units of labor from the market where firms also hire labor for production. This implies that a firm's information demand depends on its expectation of the equilibrium wage in the labor market. When a fraction $\lambda$ of firms decide to become informed in stage 1 , the equilibrium wage in stage 2 satisfies ${ }^{22}$

$$
\lambda\left(\frac{\mathbb{E}[z \mid w, s]}{w}-1\right)+(1-\lambda)\left(\frac{\mathbb{E}[z \mid w]}{w}-1\right)+\lambda \chi=1-\frac{\phi}{w},
$$

where $\lambda \chi$ represents labor demand due to information acquisition. Going through the steps in the proof of Proposition 2 when equilibrium wage is determined by (A-7), one finds that learning from wages operates as when the cost of acquiring information is exogenous and the equilibrium wage functional is given by

$$
\begin{aligned}
& \mathscr{W}_{\lambda}(\phi, \mu, \underline{s})= \begin{cases}\frac{1}{2-\lambda \chi}[\phi+\underline{z}] & \text { if } \phi<\underline{\phi}+\lambda(\bar{z}-\underline{z}) \\
\frac{1}{2-\lambda \chi}[\phi+(1-\lambda) \mathbb{E}[z \mid \mu]+\lambda \underline{z}] & \text { otherwise, }\end{cases} \\
& \mathscr{W}_{\lambda}(\phi, \mu, \bar{s})= \begin{cases}\frac{1}{2-\lambda \chi}[\phi+(1-\lambda) \mathbb{E}[z \mid \mu]+\lambda \bar{z}] & \text { if } \phi \leq \bar{\phi}-\lambda(\bar{z}-\underline{z}) \\
\frac{1}{2-\lambda \chi}[\phi+\bar{z}] & \text { otherwise. }\end{cases}
\end{aligned}
$$

From (A-8) and (A-9), one obtains that $\mathbb{E}[w \mid \mu]=\frac{1}{2-\lambda \chi}(\mathbb{E}[z \mid \mu]+\mathbb{E}[\phi \mid \mu])$. That is, the expected wage is increasing both in the prior belief $\mu$ and in the fraction of informed firms $\lambda$. The expected gain from becoming informed is given by $G(\lambda)=\left[1-\frac{\lambda(\bar{z}-\underline{z})}{\bar{\phi}-\underline{\phi}}\right][\mu \bar{z} \log \bar{z}+(1-\mu) \underline{z} \log \underline{z}-\mathbb{E}[z \mid \mu] \log (\mathbb{E}[z \mid \mu])]-\chi \mathbb{E}[w \mid \mu]$.

The expected gain function reveals that when firms hire labor to acquire information two new forces are present. First, the expected cost of acquiring information is lower when the prior belief is low, making information demand more

\footnotetext{
${ }^{22}$ We restrict our attention to strictly positive equilibrium quantities, a sufficient condition for which is $\bar{z}-\underline{z}<(1-\chi) \underline{z}-\bar{\phi}$.
} 
countercyclical. Second, more firms acquiring information raises the expected equilibrium wage, strengthening the strategic substitutability in information acquisition. 